\title{
Vitamin A and causes of maternal mortality: association and biological plausibility
}

\author{
Hala Faisel ${ }^{1}$ and Rüdiger Pittrof ${ }^{2, *}$ \\ ${ }^{1}$ PO Box 67, Abbasia, 11381 Cairo, Egypt: ${ }^{2}$ Maternal and Child Epidemiology Unit, \\ London School of Hygiene and Tropical Medicine, Keppel Street, London WC1E 7HT, UK
}

Submitted 12 August 1999: Accepted 7 January 2000

\begin{abstract}
Objective: To review the association between major causes of maternal mortality and vitamin A, trying to determine if these associations are causal in nature, and to highlight possible biological pathways that may explain vitamin A effects.

Design: Literature review, observational studies and clinical trials. The strength of association was determined by applying Bradford Hill criteria of causality.

Results: In a vitamin A deficient population, vitamin A is essential for adequate treatment of anaemia. While vitamin A does not seem to be capable of preventing uterine atony, obstetric or surgical trauma, which are important causes of haemorrhage, it might be capable of preventing or decreasing coagulopathy. Possible effects on the placenta as regards implantation, site and size are not clear. As regards pregnancy-related infections, vitamin A supplementation can improve wound healing by decreasing fibrosis and increasing transforming growth factor- $\beta$ (TFG- $\beta$ ). It can increase resistance to infection by increasing mucosal integrity, increasing surface immunoglobulin A (sIgA) and enhancing adequate neutrophil function. If infection occurs, vitamin A can act as an immune enhancer, increasing the adequacy of natural killer (NK) cells and increasing antibody production. $\beta$-carotene in its provitamin form can act as an antioxidant by decreasing endothelial cell damage (the pathognomonic feature of pre-eclampsia) and promote the vasodilator effect of nitric oxide that might bring about a better outcome of toxaemia in pregnancy. It is unlikely that vitamin A or $\beta$-carotene has an effect on obstructed labour.

Conclusions: Plausible biomedical pathways can only be constructed for obstetric haemorrhage, anaemia in pregnancy, hypertension in pregnancy and pregnancyrelated infections. A $40 \%$ reduction in the maternal mortality ratio, as observed in Nepal, is unlikely to be solely explained through the aforementioned pathways.
\end{abstract}

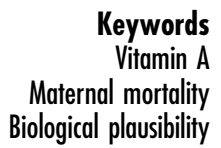

Keywords Biological plausibility
Over the last decade, the role of vitamin A in decreasing the mortality and morbidity of infectious diseases in children has been established. Now, its importance to women of reproductive age has become a focus of interest. The results of a randomized controlled trial of vitamin $\mathrm{A}$ and $\beta$-carotene supplementation to women aged 15-45 years in Nepal suggest that this supplementation resulted in a significant reduction in maternal mortality (vitamin A, 40\% reduction; $\beta$-carotene, 50\% reduction $^{1}$ ). Maternal mortality is a major public health problem in developing countries, and decreasing its burden is vital. Of the estimated 585000 maternal deaths that occur every year approximately $25 \%$ are caused by haemorrhage, $15 \%$ by infections, $13 \%$ by abortion complications, $12 \%$ by complications of hypertensive disease in pregnancy, pre-eclampsia or eclampsia and $8 \%$ by obstructed labour ${ }^{2}$. Anaemic women are at higher risk of death if these complications occur.

Only if the effect of vitamin A supplementation can be explained through biomedical pathways can we assume that the observed massive reduction in maternal mortality ratios can be attributed to the vitamin A supplementation. This review focuses on the biomedical relationship between vitamin A and the major causes of maternal mortality.

\section{Vitamin $A$ and $\beta$-carotene are not the same}

The term 'retinoids' introduced in 1976 includes carotenoids, the natural forms of vitamin A as synthetic analogues, retinol, the vitamin A alcohol (which is derived from animal sources), retinal and retinoic acid, which are the main vitamin A active metabolites. When taken orally, the body can absorb vitamin A much better than $\beta$-carotene. The bioavailability and conversion of $\beta$-carotene to vitamin A itself is very variable, being dependent on the dietary content of fat, bile salt concentration and the level of other vitamins in the body. $\beta$-carotene does not combine with specific carrier proteins and does not require receptors to perform its provitamin actions. Vitamin A, however, 
requires a specific carrier serum protein (retinol-binding protein, RBP) and specific cellular receptors to perform its actions. Clinical and subclinical infection as well as malnutrition affect RBP and receptor levels. Unlike $\beta$-carotene, vitamin A is highly toxic when taken in high doses and there is concern about its teratogenicity, although the level that could produce this in humans is still ill defined ${ }^{3}$. High doses of vitamin A are toxic because the body lacks efficient mechanisms to excrete or destroy excessive loads of it - this could cause catastrophic effects, particularly on cell membranes and possibly on the genome $^{4}$.

The antioxidant effect of vitamin $\mathrm{A}$ is largely attributed to $\beta$-carotene and other carotenoids. Therefore, while $\beta$-carotene can perform all the actions of vitamin $\mathrm{A}$, the reverse is not true.

\section{Methods}

This paper has used extensive reviews of published literature. Two databases were used: Medline, 1966 to September 1999; and BIDS, 1981 to September 1999. We searched titles, abstracts and meshes for different terms (a thesaurus search for vitamin $\mathrm{A}$ and $\beta$ carotene and a word search for vitamin A, $\beta$ carotene, retin*, caroteno*) and a thesaurus and word search (search terms: sepsis, infection, abortion, haemorrhage, hypertension, preeclampsia, eclampsia, obstructed labour and anaemia) for conditions associated with the main causes of maternal mortality. Papers were retrieved and any relevant references and review articles were followed up. Unless otherwise specified, only studies which adequately described their study population, the intervention or exposure investigated and the method of determining the outcomes were included. Specific in vitro and animal experiments were included in the review. The published literature associating vitamin A and the causes of maternal mortality is extremely limited, therefore we also drew material from unpublished reports by WHO, UNICEF and proceedings of meetings.

\section{Results}

\section{Vitamin A and obstetric postpartum or post-abortion haemorrbage}

We found no studies linking vitamin A directly to obstetric haemorrhage. Obstetric haemorrhage can be the result of: insufficient uterine contraction following delivery (uterine atony); retained products of conception (usually placental parts); trauma (whether obstetric or surgical); and dysfunction of the blood-clotting system. Despite a comprehensive review we were unable to identify a biological pathway linking vitamin $\mathrm{A} / \beta$-carotene deficiency to uterine atony (the leading cause of postpartum haemorrhage).

Abnormalities of the placenta (size, site, vessels and depth of its implantation in the uterine wall) can all lead to haemorrhage. Placental development depends on a complex and not completely understood interaction between foetal and maternal cells. Highly specific receptors for RBP (essential for the action of retinol) are expressed in the human placenta ${ }^{5}$. The level of RBP in the placenta is higher than in any other tissue of the body, including the retina ${ }^{6}$. Placental $\beta$-carotene level is almost twice as great as those found in the liver ${ }^{7}$. The presence of these high and specific levels of both vitamin A and its precursors suggest that vitamin A is essential for the placenta, or foetus, or both. It is conceivable that vitamin A deficiency could lead to problems of implantation and placental development, which in turn could lead to problems of placental separation and postpartum or post-abortion haemorrhage, or placenta praevia and placental abruption. Indeed, Sharma et $a l^{8}$ reported significantly lower levels in serum vitamin $A$ and $\beta$-carotene when comparing cases with abruptio placentae to controls. However, vitamin A deficiency may be the cause or effect of the abruption as a decrease in vitamin A can be part of an acute phase response and decreased $\beta$-carotene may be the result of increased consumption as an antioxidant to combat the oxidative stress of placental abruption.

Other causes of obstetric haemorrhage include coagulopathy. Normal coagulation depends on the adequate function of platelets, healthy endothelium and harmony between coagulation factors. Vitamin A seems to have no effect on platelet aggregation and adhesion ${ }^{9,10}$.

Endothelium injury is the starting point that triggers abnormal aggregation of the coagulation factors and leads to coagulopathy. Vitamin A appears to increase the integrity and vitality of endothelial cells ${ }^{11}$ and so could possibly prevent endothelial injury. After endothelium injury, coagulation factors start to accumulate, forming abnormal small clots that initiate a vicious cycle of disseminated intravascular coagulopathy. The increased consumption of coagulation factors leads to its exhaustion and profound haemorrhage. Vitamin A supplementation may have an effect on the clotting system through increasing thrombodulin ${ }^{12,13}$, decreasing antithrombin $\mathrm{III}^{14}$ and increasing tissue plasminogen activator ${ }^{15,16}$. This, together with the endothelial protective effect, suggests that vitamin A may be capable of preventing coagulopathy from the beginning or decrease its severity if it occurred.

\section{Vitamin $A$ and infection in pregnancy or the post-abortion or postpartum period}

Pregnancy-related infection (PRI) may result from colonization of retained products of conception (usually a part of the placenta), pre-existing infection or from unsterile invasive procedures. PRI has rarely been associated with vitamin A deficiency. In the Vanderbilt cooperative study of infant and maternal nutrition of 1945, women who experienced puerperal infection were found to have lower vitamin A levels starting from the second trimester and continuing through the postpartum examination ${ }^{17}$. 
Bacteriuria (suggestive of urinary tract infection) was observed in $80 \%$ of pregnant women presenting with clinical vitamin A deficiency ${ }^{18}$. Cases with vaginal candidasis showed a significant decrease in $\beta$-carotene concentration in exfoliated vaginal epithelial cells when compared to controls ${ }^{19}$. Pregnant women with night blindness were also twice as likely to have clinical genitourinary tract infections (lower abdominal pain, painful micturition or vaginal discharge) than controls without night blindness ${ }^{20}$. The relationship between infection and decreased vitamin A levels is, however, not that simple. Night-blind women in the study mentioned above were also more likely to be anaemic, undernourished, of lower cast and illiterate which could explain an element of the association ${ }^{20}$.

The decreased vitamin A levels found in infection might be due to decreased absorption of dietary vitamin A (due to diarrhoea or the activity of intestinal pathogen) ${ }^{21}$, decreased RBP production ${ }^{22}$ or increased loss of vitamin $\mathrm{A}$ in urine $\mathrm{in}^{23,24}$. In acute phase reaction, there is a transient decrease in the production of small molecular weight proteins, including $\mathrm{RBP}$, and an increase in the permeability of renal epithelial cells. Decreased vitamin A might also be due to increased uptake of retinol by certain tissues ${ }^{25}$.

PRI could be reduced through three main pathways: promotion of wound healing; increased resistance to infection; and immune enhancement if infection occurs. Vitamin A increases the production of TGF- $\beta$, which is involved in the promotion of wound healing ${ }^{26}$ and decreases fibrosis through suppression of the fibroblasts. These two actions may increase the integrity of the mucosal surfaces of genitourinary tracts and promote better healing of episiotomy and perineal laceration, thereby decreasing the chance of infection. Vitamin A augments natural resistance through increasing the naturally present antibodies, IgA, and promoting the function of neutrophils. Neutrophils are an important part of the first line of defence against infection as they engulf bacteria, viruses, parasites and virally infected cells. An alteration in all the components of neutrophil function has been demonstrated in vitamin A-deficient rats ${ }^{27}$.

The progress of infection depends on three factors: (i) the virulence and dose of the pathogen; (ii) host immunity; and (iii) the usage of appropriate antimicrobial agents. It is unlikely that either vitamin A deficiency or supplementation could alter the pathogen but the expected effect will be brought about through enhancing different components of the immune system.

Vitamin A helps the control of viral infection. Retinoids regulate cell growth and differentiation as well as apoptosis (programmed cell death seen in viral infection and tumour cells) ${ }^{28}$. Both the number and the activity of NK cells (which are involved in antiviral and antitumour immunity) are decreased in vitamin A deficiency ${ }^{29}$. Supplementation of vitamin A results in an increase of NK cells in children with acquired immunodeficiency syndrome
(AIDS) $)^{30}$. The methodology of this study could not be evaluated as it is published only as a meeting abstract.

The successful production of antibodies to compete with the bacteria depends on three types of cells: (i) antigenpresenting cells (APC), which present the bacterial antigen to the immune-specific cells (lymphocytes); (ii) B lymphocytes, which are responsible for antibody production; and (iii) $\mathrm{T}$ lymphocytes, which regulate the immune response. Retinol is required for growth and activation of B lymphocytes in humans ${ }^{31,32}$. Transretinoic acid augments the production of two types of antibodies: IgM (antibody of the first immune response) and IgG (antibody of the secondary immune response) ${ }^{33}$. Retinol seems to be required for the activation of $\mathrm{T}$ lymphocytes ${ }^{34}$. In vitamin A deficiency, antibody response is impaired for both T-celldependent antigen ${ }^{35}$ and T-cell-independent antigen ${ }^{36}$.

Vitamin A may decrease the incidence and severity of RPI by promoting wound healing, increasing resistance to infection and immune enhancement if infection occurs.

\section{Vitamin A and bypertensive disorders of pregnancy}

Many observational studies found a significant decrease in vitamin $\mathrm{A}$ and $\beta$-carotene in pre-eclamptic women when compared with normal pregnant women. This decrease was found both in serum ${ }^{37-40}$ as well as amniotic fluid ${ }^{41}$. The constant association between decreased retinol and $\beta$-carotene levels with pre-eclampsia, however, does not prove a causal relationship. Decreased retinol might be a part of an acute phase reaction. Many studies found decreased serum proteins in toxaemia of pregnancy ${ }^{37,42,43}$ and retinol is carried on proteins, thus its decrease could be secondary to decreased protein levels. Other studies correlated pre-eclampsia and eclampsia with increased oxygen free radicals ${ }^{44}$ and decreased antioxidant activity ${ }^{45-50}$. Thus, the decreased $\beta$-carotene might be due to increased consumption as it is an antioxidant. These observational studies are supported by an in vitro study that showed that $\beta$-carotene levels present in normal pregnant women significantly inhibited peroxide-induced vasoconstriction in a dose-dependent manner. Lower levels of $\beta$-carotene, like those present in pre-eclampsia, were not able to achieve the same effect ${ }^{51}$. A recent nested case-control study from Nepal compared 109 pregnant women with impending night blindness (xerophthalmia, XP) (cases) and without XP (controls). Plasma levels of retinol (but not $\beta$-carotene) were significantly decreased $(P<0.001)$ while rates of pre-eclampsia/eclampsia were significantly increased in patients with imminent $\mathrm{XP}^{20}$. The effect on pre-eclampsia/eclampsia was not observed after XP had developed.

Endothelial cell dysfunction is the common pathway in the pathogenesis of pre-eclampsia. $\beta$-carotene is a recognized antioxidant and free radical scavenger, and this beneficial effect is related to its provitamin activity. $\beta$-carotene and other carotenoids are much more effective antioxidants than vitamin A. Nitric oxide is a potent 
vasodilator substance that is believed to play a major role in increasing placental perfusion ${ }^{52}$. Oxidation of low density lipoprotein (LDL) decreases the release of nitric oxide. $\beta$-carotene is carried on LDL and protects it against oxidation and thus promotes nitric oxide vasodilatation. This effect has been demonstrated in animals ${ }^{53}$, in vitro ${ }^{54}$ and in humans ${ }^{55}$. A randomized, double-blind placebocontrolled trial of vitamins $\mathrm{E}$ and $\mathrm{C}$ (stronger antioxidants than $\beta$-carotene) supplementation in women at increased risk of pre-eclampsia showed a marked reduction in preeclampsia in the intervention group (adjusted odds ratio $0.39[0.17-0.90])^{56}$.

The underlying pathology in pre-eclampsia appears to be insufficient placental implantation. This is thought to lead to a relatively hypoxic maternal-foetal interface, an increased turnover of trophoblast tissue, higher xanthine and hypoxanthine concentrations and higher levels of circulating cytokines and an increased production of uric acid and free radicals ${ }^{57}$. It is unlikely that $\beta$-carotene or other antioxidants can totally correct these multiple abnormalities. In established severe cases it is unlikely to restore normality except by delivery. We do not believe that $\beta$-carotene alone can restore normality in established pre-eclampsia but it may contribute to a more favourable outcome. As of September 1999, it remains biologically plausible that $\beta$-carotene, by decreasing endothelial cell damage and promoting vasodilatation, could have the potential to decrease the incidence and severity of pre-eclampsia.

\section{Vitamin A and obstructed labour}

Conceptually obstructed labour can be caused by problems of the passenger (foetus), the passages (bony pelvis, cervix and vagina) and the forces (uterine contraction). Despite the best of intentions and imaginative effort, it was not possible to identify any studies linking obstructed or prolonged labour and vitamin A deficiency.

A hypothetical pathway may be related to the central nervous system (CNS) of the foetus. Vitamin A is involved in CNS development and impaired CNS development is known to decrease the frequency of malposition in labour. However, no data was found to support this hypothesis. Increase in size of the foetus or macrosomia is a known cause of obstructed labour, but there is no data reporting abnormal decreased weight with increased vitamin A supplementation. Decreased size is associated with malpresentation and obstructed labour. Low cord vitamin A has been constantly associated with decreased birth weight ${ }^{58-63}$. Maternal serum of low birth weight newborns did not significantly differ from mothers of normal birth weight newborns ${ }^{64,65}$. Birth weight was not altered by daily vitamin A supplementation during pregnancy for more than 12 weeks ${ }^{66}$. It is to be noted that these studies used different case definitions and did not differentiate between prematurity and intrauterine growth restriction. Thus, no conclusive evidence can be drawn from them. From available information the determining factor seems to be the availability of vitamin A for utilization by the growing foetus rather than the maternal serum level of vitamin A.

A further pathway could be related to uncoordinated or insufficient myometrial activity (forces) and vitamin A deficiency. Yet, no evidence was found for this pathway or for any effect of vitamin A deficiency on the soft and bony tissues of the pelvic passage.

\section{Vitamin A and anaemia during or after pregnancy} Very severe anaemia (haemoglobin of less than $4 \mathrm{~g} \mathrm{dl}^{-1}$ ) can lead to heart failure and death especially during a metabolically stressful condition such as delivery. Anaemia increases the likelihood of mortality in cases of haemorrhage. However, anaemia associated with vitamin A deficiency may be more important than generally perceived - vitamin A deficiency affects water metabolism with resulting haemoconcentration and haemoglobin levels may be normal when 'total body haemoglobin' is low.

Anaemia in pregnancy is largely attributed to iron deficiency, malaria and hookworm infections. Vitamin A increases the integrity of the epithelial cells of the intestinal tract with resultant better absorption of iron. A recent study suggested that vitamin A can increase the absorption of iron in fortified food by two-fold and $\beta$-carotene by three-fold and that it prevents the inhibitory effect of phytates on iron absorption in humans ${ }^{67}$. The results of this study need to be interpreted with caution as the method of food processing used may have affected iron absorption rates. Vitamin A supplementation to pregnant, poorly nourished women results in an increase in circulating iron and transferrin and facilitates the delivery of iron to bone marrow ${ }^{68,69}$. Vitamin A is necessary for the adequate formation of red blood cells. Impaired red blood cell formation has been demonstrated in the form of poikilocytosis and anisocytosis (abnormal size, shape and staining characters) when 10 male volunteers were fed with a vitamin A-deficient diet for 188 days $^{70}$. In vitro studies indicate that retinoids influence the growth and differentiation of various precursors of red blood cells ${ }^{71}$.

Randomized controlled trials in India ${ }^{66}$ and Indonesia ${ }^{69}$ showed that the combination of vitamin $\mathrm{A}$ and iron supplementation resulted in a significant and important reduction of the prevalence of anaemia in pregnancy when compared with vitamin A or iron supplementation alone.

Vitamin A is necessary for haemopoiesis and iron metabolism. It is likely that vitamin A supplementation can reduce anaemia prevalence in vitamin A-deficient pregnant women.

\section{Conclusions}

This paper addressed the relationship between vitamin $\mathrm{A}$ and the main causes of maternal mortality. Plausible 
biomedical pathways could be constructed for obstetric haemorrhage, anaemia in pregnancy, hypertension in pregnancy and pregnancy-related infections. While the evidence presented in this review does not permit estimating the effect of vitamin $\mathrm{A} / \beta$-carotene supplementation on maternal mortality, it is the impression of the authors that a $40 \%$ reduction in maternal mortality ratio as observed in Nepal cannot be solely explained through the above described pathways. If vitamin $\mathrm{A}$ does reduce the risk of maternal mortality it is likely to do so through multiple pathways. Some of them will include alterations in placentation (inappropriate placentation can be expected to be associated with an increased risk of hypertension in pregnancy, post-abortion haemorrhage and obstetric haemorrhage). If this were the case, vitamin A supplementation during the period of placentation (first trimester) rather than in the second and third trimester may be the explanation of the reduced maternal mortality observed in the Nepal study. This would have important implications for programme planning, as vitamin A supplementation during the conventional antenatal period may not reproduce the beneficial effects of the Nepal study.

Politicians and health planners may be well advised to await the results of further trials before implementing large-scale supplementation programmes. Reducing maternal mortality may require more than vitamin A supplementation in the antenatal clinic.

\section{Acknowledgements}

We would like to thank Dr Suzane Filteau, Institute of Child Health, University of London and Dr Gustaaf A. Dekker, Maternal and Foetal Medicine Division, Free University Hospital for their helpful comments and Ms Caroline Leicester for secretarial support.

\section{References}

1 Keith P, West KP, Joanne Katz J, et al. Double blind, cluster randomised trial of low dose supplementation with vitamin A or $\beta$-carotene on mortality related to pregnancy in Nepal. BMJ 1999; 318: 570-5.

2 WHO. Mother and Baby Package, Implementing Safe Motherhood in Countries. Document No. WHO/FHE/ MSM/94.11. Geneva, World Health Organization, 1994; 2.

3 Hathcock JN, Hattan DG, Jenkins MY, et al. Evaluation of vitamin A toxicity. Am. J. Clin. Nutr. 1990; 52: 183-202.

4 Bates CJ. Vitamin A. Lancet 1995; 345: 31-5.

5 Moden M. Vitamin A in embryonic development. Nutr. Rev. 1990; 52: S3-12.

6 Smeland S, Bjerknes T, Malaba L, et al. Tissue distribution of the receptor for plasma retinol-binding protein. Biochem.J. 1995; 305(2): 419-24.

7 Dimenstein R, Trugo NM, Donangelo CM, Trugo LC, Anastacio AS. Effect of subadequate maternal vitamin-A status on placental transfer of retinol and beta-carotene to the human fetus. Biol. Neonate 1996; 69(4): 230-4.

8 Sharma SC, Bonnar J, Dostalova. Comparison of blood levels of vitamin A, beta-carotene and vitamin $\mathrm{E}$ in abruptio placentae with normal pregnancy. Int. J. Vitam. Nutr. Res. 1986; 56(1): 3-9.

9 Calzada C, Bruckdorfer KR, Rice Evans CA. The influence of antioxidant nutrients on platelet function in healthy volunteers. Atherosclerosis 1997; 128(1): 97-105.

10 Lee JY, Mak CP, Wang BJ, Chang WC. Effects of retinoids on endothelial cell proliferation, prostacyclin production and platelet aggregation. J. Dermatol. Sci. 1992; 3(3): 15762.

11 Bekyarova G, Yankova T, Galunska B. Increased antioxidant capacity, suppression of free radical damage and erythrocyte aggregatability after combined application of alphatocopherol and FC-43 perfluorocarbon emulsion in early postburn period in rats. Artif. Cells Blood Substit. Immobil. Biotechnol. 1996; 24(6): 629-41.

12 Horie S, Kizaki K, Ishii H, Kazama M. Retinoic acid stimulates expression of thrombomodulin, a cell surface anticoagulant glycoprotein, on human endothelial cells. Differences between up-regulation of thrombomodulin by retinoic acid and cyclic AMP. Biochem. J. 1992; 281(1): 14954.

13 Shibakura M, Koyama T, Saito T, et al. Anticoagulant effects of synthetic retinoids mediated via different receptors on human leukemia and umbilical vein endothelial cells. Blood 1997; 90(4): 1545-51.

14 Sanders TA, Vickers M, Haines AP. Effect on blood lipids and haemostasis of a supplement of cod-liver oil, rich in eicosapentaenoic and docosahexaenoic acids, in healthy young men. Clin. Sci. 1981; 61(3): 317-24.

15 Thompson EA, Nelles L, Collen D. Effect of retinoic acid on the synthesis of tissue-type plasminogen activator and plasminogen activator inhibitor-1 in human endothelial cells. Eur. J. Biochem. 1991; 201(3): 627-32.

16 Back O, Nilsson TK. Retinoids and fibrinolysis. Acta Derm. Venereol. 1995: 75(4): 290-2.

17 McGanity WJ, Cannon RO, Bridgforth EB, et al. The Vanderbilt cooperative study of maternal and infant nutrition. IV. Relationship of obstetric performance to nutrition. Am. J. Obstet. Gynecol. 1945; 67: 501-27.

18 Edmond C, Clemmesen SV. On parental vitamin A treatment of dysaptation (nyctalo-hemeralopia) in some pregnant women. Acta Med. Scand. 1936; 89: 69-92.

19 Mikhail MS, Palan PR, Basu J, Anyaegbunam A, Romney SL. Decreased beta-carotene levels in exfoliated vaginal epithelial cells in women with vaginal candidiasis. Am. J. Reprod. Immunol. 1994; 32(3): 221-5.

20 Christian P, West KP, Khatry SK, et al. Night blindness of pregnancy in rural Nepal - nutritional and health risks. Int.J. Epidemiol. 1998; 27(2): 231-7.

21 Semba RD. Vitamin A, immunity, and infection. Clin. Infect. Dis. 1994; 19(3): 489-99.

22 Rosales FJ, Ritter SJ, Zolfaghari R, Smith JE, Ross AC. Effects of acute inflammation on plasma retinol, retinol-binding protein, and its mRNA in the liver and kidneys of vitamin Asufficient rats. J. Lipid Res. 1996; 37(5): 962-71.

23 Alvarez JO, Salazar LE, Kohatsu J, Miranda P, Stephensen CB. Urinary excretion of retinol in children with acute diarrhoea. Am. J. Clin. Nutr. 1995; 61(6): 1273-6.

24 Filteau SM, Morris SS, Abbott RA, et al. Influence of morbidity on serum retinol of children in a community-based study in northern Ghana. Am. J. Clin. Nutr. 1993; 58(2): 192-7.

25 Willumsen JF, Simmank K, Filteau SM, Wagstaff LA, Tomkins AM. Toxic damage to the respiratory epithelium induces acute phase changes in vitamin A metabolism without depleting retinol stores of South African children. J. Nutr. 1997; 127(7): 1339-43.

26 Szabo G, Puppolo M, Verma B, Catalano D. Regulatory potential of ethanol and retinoic acid on human monocyte functions. Alcohol. Clin. Exp. Res. 1994; 18(3): 548-54.

27 Twining SS, Schulte DP, Wilson PM, Fish BL, Moulder JE. 
Vitamin A deficiency alters rat neutrophil function. $J$. Nutr. 1997; 127(4): 558-65.

28 Semba RD. The role of vitamin A and related retinoids in immune function. Nutr. Rev. 1998; 56(1 part 2): S38-48.

29 Zhao Z, Ross AC. Retinoic acid repletion restores the number of leukocytes and their subsets and stimulates natural cytotoxicity in vitamin A-deficient rats. J. Nutr. 1995; 125(8): 2064-73.

30 Hussey G, Huges J, Potgieter S, et al. Vitamin A status and supplementation and its effects on immunity in children with Aids. Abstracts of the XVII International Vitamin A Consultative Group Meeting, Guatemala City. Washington, DC: International Life Science Institute, 1996; 6 (abstract).

31 Buck J, Ritter G, Dannecker L, et al. Retinol is essential for growth of activated human B cells. J. Exp. Med. 1990; 171(5): $1613-24$

32 Blomhoff HK, Smeland EB, Erikstein B, et al. Vitamin A is a key regulator for cell growth, cytokine production, and differentiation in normal B cells. J. Biol. Chem. 1992; 267(33): 23988-92.

33 Ballow M, Wang W, Xiang S. Modulation of B-cell immunoglobulin synthesis by retinoic acid. Clin. Immunol. Immunopathol. 1996; 80(3/2): S73-81.

34 Garbe A, Buck J, Hammerling U. Retinoids are important cofactors in T cell activation. J. Exp. Med. 1992; 176(1): 10917.

35 Semba RD, Muhilal, Scott AL, et al. Effect of vitamin A supplementation on immunoglobulin G subclass responses to tetanus toxoid in children. Clin. Diagn. Lab. Immunol. 1994; 1(2): 172-5.

36 Pasatiempo AM, Bowman TA, Taylor CE, Ross AC. Vitamin A depletion and repletion: effects on antibody response to the capsular polysaccharide of Streptococcus pneumoniae, type III (SSS-III). Am.J. Clin. Nutr. 1989; 49(3): 501-10.

37 Basu RJ, Arulanantham R. A study of serum protein and retinol levels in pregnancy and toxaemia of pregnancy in women of low socio-economic status. Indian J. Med. Res. 1973; 61(4): 589-95.

38 Jendryczko A, Drozdz M. Plasma retinol, beta-carotene and vitamin $\mathrm{E}$ levels in relation to the future risk of preeclampsia. Zentralbl. Gynakol. 1989; 111(16): 1121-3.

39 Mikhail MS, Anyaegbunam A, Garfinkel D, et al. Preeclampsia and antioxidant nutrients: decreased plasma levels of reduced ascorbic acid, alpha-tocopherol, and beta-carotene in women with preeclampsia. Am.J. Obstet. Gynecol. 1994; 171(1): 150-7.

40 Ziari SA, Mireles VL, Cantu CG, et al. Serum vitamin A, vitamin $\mathrm{E}$, and beta-carotene levels in preeclamptic women in northern Nigeria. Am. J. Perinatol. 1996; 13(5): 287-91.

41 Koskinen T, Valtonen P, Lehtovaara I, Tuimal R. Amniotic fluid retinol concentration in late pregnancy. Biol. Neonate 1986; 49: 81-4.

42 Studd JW, Shaw RW, Bailey DE. Maternal and fetal serum protein concentration in normal pregnancy and pregnancy complicated by proteinuric pre-eclampsia. Am. J. Obstet. Gynecol. 1972; 114(5): 582-8.

43 Choudhuri SK. Serum protein changes in toxemia of pregnancy. J. Indian Med. Assoc. 1969; 53: 334-44.

44 Wickens D, Wilkins MH, Lunec J, Ball G, Dormandy TL. Free radical oxidation (peroxidation) products in plasma in normal and abnormal pregnancy. Ann. Clin. Biochem. 1981; 18(3): 158-62.

45 Shaarawy M, Aref A, Salem ME, Sheiba M. Radical-scavenging antioxidants in pre-eclampsia and eclampsia. Int.J. Gynaecol. Obstet. 1998; 60(2): 123-8.

46 Poranen AK, Ekblad U, Uotila P, Ahotupa M. Lipid peroxidation and antioxidants in normal and pre-eclamptic pregnancies. Placenta 1996; 17(7): 401-5.

47 Wang Y, Walsh SW. Antioxidant activities and mRNA expression of superoxide dismutase, catalase, and glutathione peroxidase in normal and preeclamptic placentas. $J$. Soc. Gynecol. Investig. 1996; 3(4): 179-84.

48 Alexa ID, Jerca L, Gheorghita V, et al. The role of lipid peroxidation and of the antioxidant systems in normal pregnancy and in pre-eclampsia. Rev. Med. Chir. Soc. Med. Nat. Iasi 1996; 100(3/4): 84-9.

49 Uotila JT, Tuimala RJ, Aarnio TM, Pyykko KA, Ahotupa MO Findings on lipid peroxidation and antioxidant function in hypertensive complications of pregnancy. $\mathrm{Br} . \mathrm{J}$. Obstet. Gynaecol. 1993; 100(3): 270-6.

50 Davidge ST, Hubel CA, Brayden RD, Capeless EC, McLaughlin MK. Sera antioxidant activity in uncomplicated and preeclamptic pregnancies. Obstet. Gynecol. 1992; 79(6): 897901.

51 Cueto SM, Romney AD, Wang Y, Walsh SW. Beta-carotene attenuates peroxide-induced vasoconstriction in the human placenta. J. Soc. Gynecol. Investig. 1997; 4(2): 64-71.

52 Kingdom J, Sibley C. The placenta. In: Hillier SG, Kitchener HC, Neilson JP, eds. Scientific Essentials of Reproductive Medicine. London: WB Saunders, 1996; 312-28.

53 Keaney JF Jr, Gaziano JM, Xu A, et al. Dietary antioxidants preserve endothelium-dependent vessel relaxation in cholesterol-fed rabbits. Proc. Natl. Acad. Sci. USA 1993; 90(24): 11880-4.

54 Reaven PD, Ferguson E, Navab M, Powell FL. Susceptibility of human LDL to oxidative modification. Effects of variations in beta-carotene concentration and oxygen tension. Arterioscler. Thromb. 1994; 14(7): 1162-9.

55 Gilligan DM, Sack MN, Guetta V, et al. Effect of antioxidant vitamins on low density lipoprotein oxidation and impaired endothelium-dependent vasodilatation in patients with hypercholesterolemia. J. Am. Coll. Cardiol. 1994; 24(7): 1611-17.

56 Chappell LC, Seed PT, Briley AL, et al. Effect of antioxidants on the occurrence of pre-eclampsia in women at increased risk: a randomised trial. Lancet 1999; 354: 810-16.

57 Many A, Hubel CA, Roberts JM. Hyperuricemia and xanthine oxidase in preeclampsia, revisited. Am. J. Obstet. Gynecol. 1996; 174(1): 288-91

58 Brandt RB, Mueller DG, Schroeder JR, et al. Serum vitamin A in premature and term neonates. J. Pediatr. 1978; 92(1): $101-4$.

59 Shenai JP, Chytil F, Jhaveri A, Stahlman MT. Plasma vitamin A and retinol-binding protein in premature and term neonates. J. Pediatr. 1981; 99(2): 302-5.

60 Navarro J, Causse MB, Desquilbet N, Herve F, Lallemand D. The vitamin status of low birth weight infants and their mothers. J. Pediatr. Gastroenterol. Nutr. 1984; 3(5): 744-8.

61 Shah RS, Rajalakshmi R. Vitamin A status of the newborn in relation to gestational age, body weight, and maternal nutritional status. Am. J. Clin. Nutr. 1984; 40(4): 794-800.

62 Yassai MB, Malek F. Newborns vitamin A in relation to sex and birth weight. J. Trop. Pediatr. 1989; 35(5): 247-9.

63 Ghebremeskel K, Burns L, Burden TJ et al. Vitamin A and related essential nutrients in cord blood: relationships with anthropometric measurements at birth. Early Hum. Dev. 1994; 39(3): 177-88.

64 Dison PJ, Lockitch G, Halstead AC, et al. Influence of maternal factors on cord and neonatal plasma micronutrient levels. Am. J. Perinatol. 1993; 10(1): 30-5.

65 Rondo PH, Abbott R, Rodrigues LC, Tomkins AM. Vitamin A, folate, and iron concentrations in cord and maternal blood of intra-uterine growth retarded and appropriate birth weight babies. Eur. J. Clin. Nutr. 1995; 49(6): 391-9.

66 Panth M, Shatrugna V, Yasodhara P, Sivakumar B. Effect of vitamin A supplementation on haemoglobin and vitamin A levels during pregnancy. Br. J. Nutr. 1990; 64(2): 351-8.

67 Garcia Casal MN, Layrisse M, Solano L, et al. Vitamin A and 
beta-carotene can improve nonheme iron absorption from rice, wheat and corn by humans. J. Nutr. 1998; 128(3): 64650.

68 Vijayalakshami P, Lakshami RN. Effect of vitamin A and iron supplementation on serum levels of these nutrients among expectant mothers. Int. J. Nutr. Diet. 1983; 20: 149-52.

69 Suharno D, West CE, Muhilal, et al. Supplementation with vitamin A and iron for nutritional anaemia in pregnant women in West Java, Indonesia. Lancet 1993; 342: 1225-8.
70 Wagner KH. Die experimentelle Avitaminose A beim Menschen. Hoppe Seyler. Z. Physiol. Chem. 1940; 264: 135. (Cited in eds Hodges RE, Sauberlich HE, Canham JE et al. Hematopiotic studies in vitamin A deficiency. Am.J. Clin. Nutr. 1978; 31: 876-85.)

71 Blomhoff HK, Someland EB. Role of retinoids in normal hematopoiesis and the immune system. In: Blomhoff $\mathrm{R}$ ed. Vitamin A in Health and Disease. New York: Marcel Dekker, 1994; 455-9. 